\title{
Design the Piston of Internal Combustion Engine by ProlENGEER
}

\author{
Shuoguo Zhao \\ Mechatronics Department \\ Handan Polytechnic College,Handan Hebei 056005, China \\ zhaoshuguo@yahoo.com.cn
}

Keywords: piston; ProlENGEER; optimal design.

\begin{abstract}
The piston is a "heart" of the engine and its working condition is the worst one of the key parts of the engine in the working environment. So it is very important for structural analysis of the piston. This paper analies and calculates the piston by Pro\ENGEER software to gain a result, which improves and optimizes the structure of the piston.
\end{abstract}

\section{Introduction}

In recent years, digital simulation technology has been developing rapidly. Virtual piston is established by Pro\ENGEER easily. As is well-known that virtual piston can simulate the product all kinds of chatacter in the real environment. The results of simulation will be used to optimize piston design, in order to shorten the cycle, reduce the cost and improve the quality of products.

Piston is one of the key components in a motor and it closely relates to the machine performance, carbon emissions and the economy. With the engine higher speed and strengthen developing, its higher pressure ratio and higher power improve constantly. Pistons work condition is more and more bad, so its reliability has becomed the key factors to improve engine reliability. Structure and working environment of pistons are very complex. In the working environment, the pistons will produce stress and deformation because of the periodic load effect, which are from high gas pressure, high speed reciprocating motion from the inertia force, lateral pressure, friction and so on. Burning of the high pressure gas products high temperature, which makes piston expands in order that its interior produces thermal stress and thermal deformation. The thermal deformation and mechanical deformation will cause piston cracks, tortuosity, etc. Therefore, it is essential to analy the stress field, temperature field, heat transfer, thermal load and mechanical load coupling of piston in order to lower the heat load and improve the thermal stress distribution and improve its working reliability during the piston designed. Analysis method of the finite element provides a powerful calculation tool, which is better than test method and theory analysis method and has become an important means for internal combustion engine performance study.

\section{Piston Structure Design}

\section{Design Engine Piston}

According to the design parameters, we use Pro/E software to establish the piston model. In this paper, we consider the symmetry of the piston geometry structure and adopt 1 /4 model to analy the piston, which can simplify the calculation process of finite element, shorten the time of analysis and also can get a good analysis result. We establish piston model by Pro/E as shown in figure 1 .

\section{Model Parameter Settings}

Select the "Mechanica" in the "application" of menu and set the parameters. First, set model material for aluminum alloy AL6061. Then, set the tensile strength definition for $240 \mathrm{Mpa}$, tensile stress limit definition for $290 \mathrm{Mpa}$, surface finish for already glazing.

\section{Defining Constraints and Createing Load}

Piston pin hole is constrainted by displacemen and symmetry in order to make the pin hole produce the correct constraint condition.

By analysis of the piston working process, we find that stress and deformation of the piston is the 
most serious under the steady speed conditions when thegas-fired pressure is the maximum. At the same time, the strength of piston is especially outstanding. Therefore, it is essensial to choose the piston under the rated power and we only analy distribution force in the axis of the force, including the maximum explosion pressure and reciprocating inertia force. Pressure load of piston is that gas pressure effects piston top surface by high pressure in the cylinder. For simplified analysis, we can use the steady state process, but cannot ignore the effect that combustion power stroke products impact load for piston. Using cylinder fluid dynamics simulation results, we can calculate that average pressure of piston top is 9Mpa in a working cycle, which will be surface pressure load. Such as shown in figure 2.

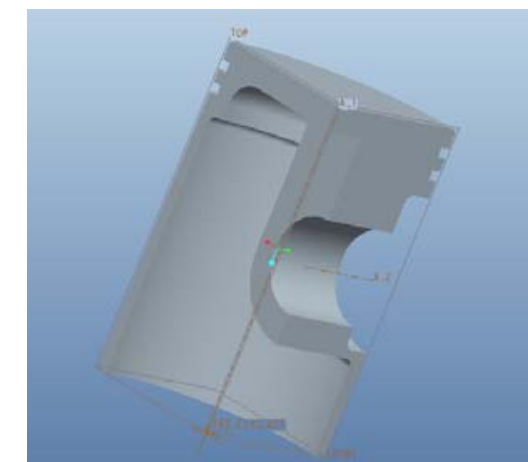

Fig1 part of the piston model

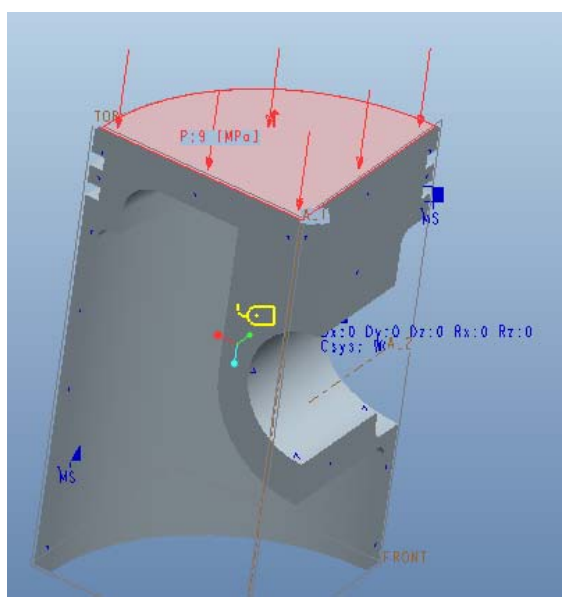

Fig2 piston the results of calculation

\section{Computation and Mechanical Analysis}

\section{Mechanical Analysis of The Piston}

After the simulation model established, it can get strain distribution and fatigue analysis under the effect of mechanical load by operating the mechanical program. The simulation results of piston are shown as in figure 3.
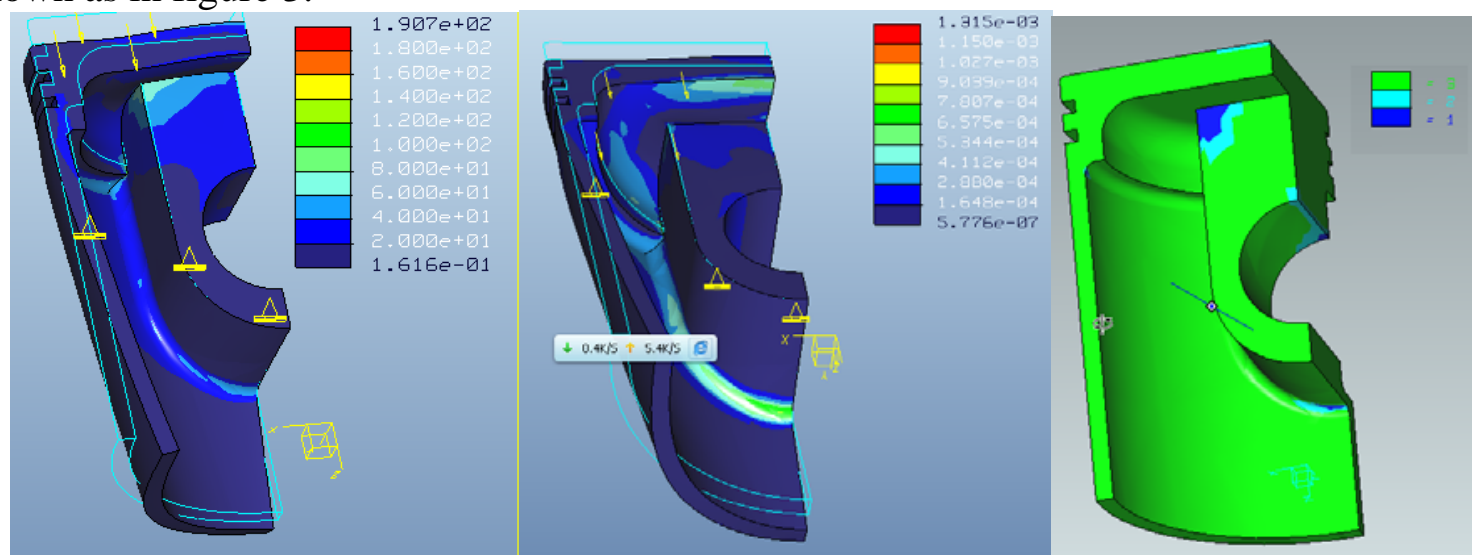

Fig3 Stress, strain and fatigue

Piston is affected by gas explosion pressure and the reciprocating inertia force and their common feature is that they effect along the axis direction of the piston, so the axis direction of piston bears the bigger load. From the Fig4, we can see that the maximum stress appears the centre of piston pin top, which is accordance to engine design manual. Piston pin top is the easiest fracture parts. When piston operating, the maximum equivalent stress value of piston pin is about $8 \mathrm{M} \mathrm{Pa}$ and equivalent stress value of the other parts is under6 $\mathrm{M}$ Pa. From the analysis of strain, the maximum strain appears in the piston top, the maximum strain is about $0.06 \%$. The results of these simulations analysis provides a strong theory basis for failure problems of the piston.

\section{The piston Thermal Analysis}

Create a Thermal Load. When Pistons are operating, they directly touch the high temperature gas and their transient temperature can reach more than $2500 \mathrm{~K}$ and generates the $18 \mathrm{KW}$ power. 
Piston is heated seriously and its heat transfer coefficient is $167 \mathrm{w} / \mathrm{m}{ }^{\circ} \mathrm{C}$ and its heat dissipation condition is poor, so the piston temperature can reach $600 \sim 700 \mathrm{~K}$ approximately and the temperature distributes unevenly. On the basis of these conditions, we will make thermal analysised for the piston.

Results and Analysis. Through the analysis of the operation, we can get the pistons temperature field distribution, as shown in figure4. The piston temperature distibutes unevenly. The maximum steady state temperature of the piston is $2500 \mathrm{~K}$ under the temperature effect of the repeated changes in the high temperature gas. The highest temperature appears the top surface of the piston. The temperature of piston pin changs between $700 \mathrm{~K}$ and $800 \mathrm{~K}$. The temperature of the first ring groove is the important evaluation index of thermal load of piston and its temperature is between $1300 \mathrm{~K}$ and $1500 \mathrm{~K}$. The highest temperature differs by $1800 \mathrm{~K}$ from the minimum temperature, which will make piston cause larger thermal stress and thermal damage.

From the diagram, we can find the piston temperature is gradient descent along the piston axis direction from up to down, but the temperature change of piston skirt is lesser. The diagram indicates that thermal deformation of the piston is bigger from bottom to top and heat distortion of the bottom is minimum. These findings are consistent with domestic researchers results.

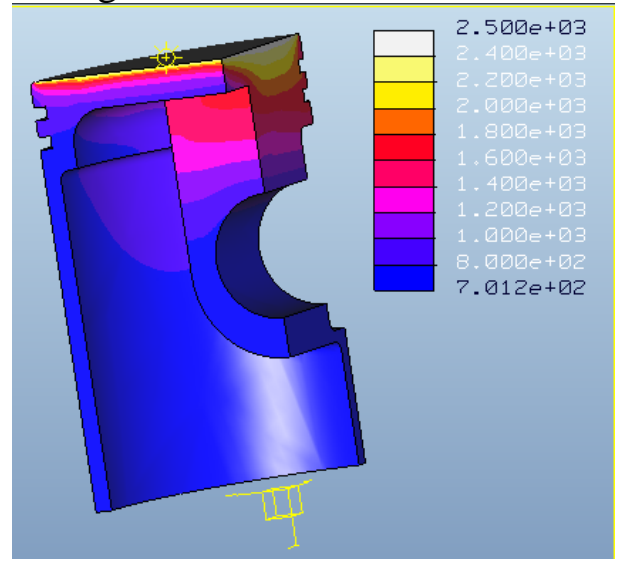

Fig4 pistons temperature field distribution

\section{Summary}

Optimal design is the essence of structure analysis and it is also the final stage of the analysis. Through the given parameter scope and general optimization goal, we Comprehensively use the front analysis result to gain the most optimized results. As shown in figure5, the result meets the design requirements.

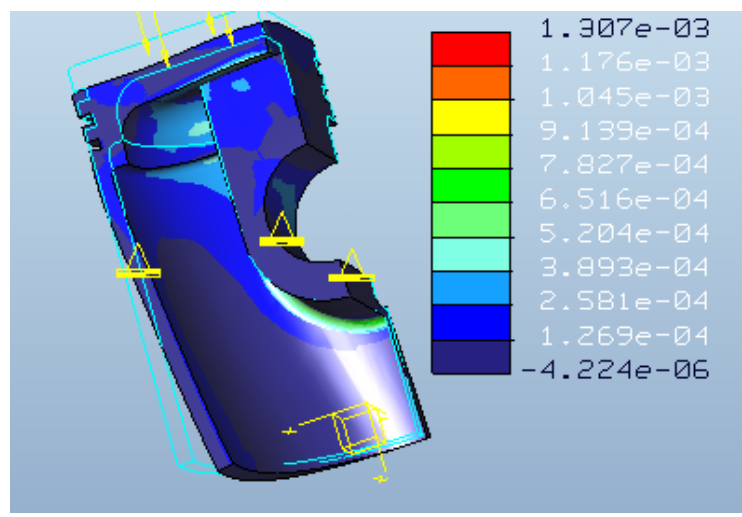

Fig5 optimal design

\section{References}

[1] Zhang Yonggang, MA Xuejun, MA Chengxin, SONG Shufeng. Application of Finite Element Analysis and FatigueEstimation in Developing Piston, Diesel Engine, Vol.27(2005)No.3:21-23(in chinese). 
[2] Lei Jilin, Shen Lizhong, Bi Yuhua, Shen Yinggang, Yan Wensheng, Zhang Wei. Application of Fin ite Element Analytic Method in Internal Combustion Engine Piston Research. Tractor \& Farm T ransporter. 2005,4:10-13(in chinese).

[3] Tetsuhiro Hosokawa, Hiroshi Tsukada, Yorishige Maeda. Development of computer aided eng ineering for piston design. SAE Paper. 890775:916 922.

[4] Robinson D, Palan inathan R. Thermal analysis of piston casting using3- D finite element method. Finite Elements in Analysis and Design.2001, 37: 85 95.

[5] Tetsuhiro Hosokawa, Hiroshi Tsukada, Yorishige Maeda. Development of computer aided engineering for piston design. SAE Paper 890775:916 922.

[6] RobinsonD, Palaninathan R. Thermal analysis of piston casting using3- D finite element method. Finite Elements in Analysis and Design2001, 37: 85 95 